\title{
GUMMA OF THE LIVER IN CONGENITAL SYPHILIS
}

\author{
BY \\ D. WHITEHOUSE and W. V. MACFARLANE \\ From the Departments of Child Health and Venereology, Newcastle General Hospital, Newcastle upon Tyne
}

(RECEIVED FOR PUBLICATION MARCH 5, 1957)

Modern methods of serological testing for syphilis in pregnancy combined with highly efficient antisyphilitic therapy should now be making congenital syphilis a relatively rare disease. In addition, past reports have frequently emphasized the ease with which gummata of the liver, and, indeed, elsewhere, may be misdiagnosed. In these circumstances unusual manifestations of this condition are more than ever likely to be missed, and for this reason we feel our recent experience with gumma of the liver should be described.

\section{Case Report}

W.G., a boy of 6 years, the only son of parents both aged 40 years living in a small market town, was sent to the Out-patient Department with the suggested diagnosis of leukaemia. His history was of vague ill-health for one year, beginning with an episode called by his parents 'the blues', consisting of a period of extreme sensitivity to cold, with shivering and a blue-black appearance of the face and legs during the winter weather. This was followed by episodes of loss of appetite, pallor and pain in the left side of the abdomen lasting three or four weeks, but apparently without fever and without vomiting.

On examination he was pale, lethargic and febrile. The main physical sign consisted of a striking enlargement of the liver, especially the left lobe. The edge was well defined, reaching half-way to the umbilicus, and its surface was nodular. There was no generalized lymphadenopathy and the spleen was not palpable. The provisional diagnosis was secondary neoplasm, involving the liver.

During his first few days in hospital he showed a sustained fever averaging $100^{\circ} \mathrm{F}$. and had a persistently high E.S.R. to $100 \mathrm{~mm}$. in one hour. The blood picture was as follows: $\mathrm{Hb} 73 \%$, P.C.V. 35\%, M.C.H.C. $31 \%$, W.B.C. $7,000 /$ c.mm. (polymorphs $47 \%$, eosinophils $2 \%$, lymphocytes $42 \%$, abnormally large lymphocytes $5 \%$ and monocytes $7 \%$ ).

Liver function was tested by zinc sulphate, thymol turbidity, thymol flocculation and cephalin cholesterol tests, which were all normal. The alkaline phosphatase was $27 \cdot 5$ units (Jenner and Kay) and the serum bilirubin was $0.3 \mathrm{mg} . / 100 \mathrm{ml}$.
Mantoux testing (10 international units) was negative and $x$-ray examination of the chest, abdomen and long bones showed no abnormality.

At laparotomy the liver was found to be studded throughout with round greyish nodules with a large mass coalescing in the left lobe to cause the enlargement which constituted the presenting physical sign. Careful search of the abdomen did not reveal any primary neoplasm, but the findings were thought to bear out the original diagnosis.

Histology. The report, by Dr. J. Hart-Mercer, was as follows :

'There is no sign of neoplasm. The nodular lesion is essentially a necrotizing chronic granuloma with almost complete obliteration of the local parenchyma. Included in the specimen are surviving areas of liver tissue but these are also being invaded by the granulomatous process which is spreading here mainly by the lymphoreticular tissue of the larger portal tracts. With a picture of necrotic foci rather resembling caseation associated with epithelioid reaction and Langhans giant cells, tubercle has to be considered.'

Serological Tests. As the Mantoux test was again negative a Wassermann reaction was performed and found to be positive. Blood Wassermann tests were repeatedly strongly positive, but examination of the cerebrospinal fluid revealed no evidence of syphilis. The parents were then investigated and the mother was found to have latent spyhilis. She had a strongly positive blood Wassermann reaction but normal cerebrospinal fluid with a negative Wassermann reaction. There was no clinical evidence of syphilis. The father was entirely negative. Detailed review of the child revealed no other sighs of congenital syphilis, and, in particular, re-examination of radiographs of the long bones showed no evidence of osteoperiostitic changes.

Treatment. Treatment was initially with potassium iodide, starting with 1 grain daily and increasing rapidly up to $\mathbf{1 0}$ grains three times daily. To this was added bismuth metal suspension ('chlorostab' brand) beginning with $50 \mathrm{mg}$. weekly and increasing gradually until the patient was receiving $150 \mathrm{mg}$. per injection, which was given deeply intramuscularly in the upper outer quadrant of alternate buttocks. 


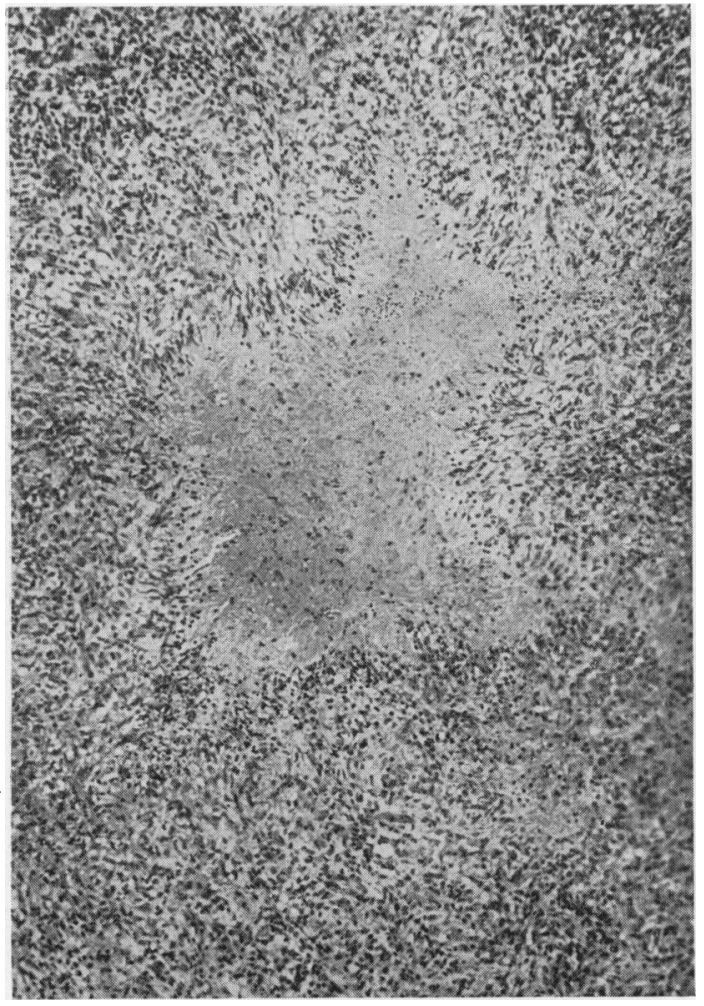

FIG. 1.-A small gummatous nodule in the liver. $(\times 90)$

An aqueous crystalline penicillin preparation was started on the tenth day after commencing treatment, beginning with 5,000 units six hourly and increasing to 50,000 units per injection in a further 10 days. After two weeks a delayed absorption product ('prolopen', Messrs. Glaxo Laboratories) was given once daily until a total of 6.3 mega units of penicillin had been administered.

After nearly three months, out-patient treatment was begun, consisting of $0.2 \mathrm{ml}$. bismuth weekly for 10-week periods alternating with 900,000 units penicillin per week for seven-week periods. A total of six courses of bismuth and 39 mega units of penicillin has been given to date.

Even the short pre-penicillin course produced a dramatic decrease in the size of the liver, and by the time penicillin was begun it had receded to only half an inch below the costal margin.

Liver function tests on discharge from hospital and repeated one year later were normal and the boy has now attained a negative serology for syphilis.

\section{Comment}

Nabarro (1954), with his very extensive experience of congenital syphilis, states that hepatic gummata

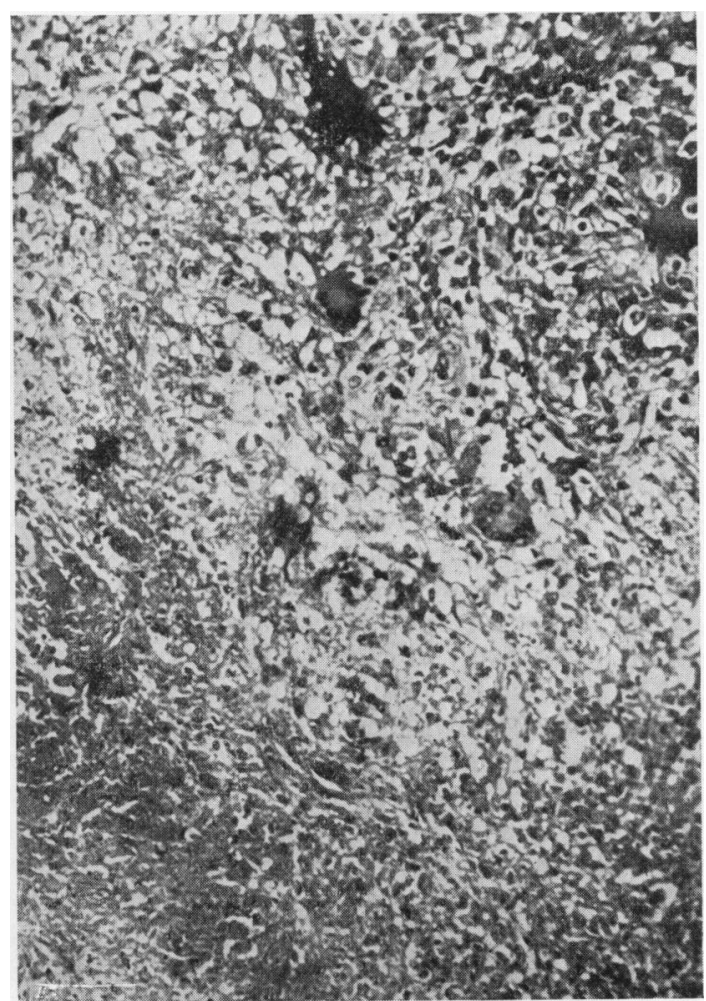

FIG. 2.-High-power view of liver showing multinucleate giant cells. $(\times 190)$

are of great rarity in this variety of the disease. $\mathrm{He}$ says that the usual histological picture in the liver consists of a diffuse small cell infiltration occurring in utero and in the first months of life, succeeded later in some cases by fibrosis or cirrhosis varying from a microscopic lesion to complete destruction of the liver architecture. He quotes only two cases of gumma of the liver, described by Carpenter (1901) and Hutinel (1926), the former in an infant aged 8 months and the latter in a newborn infant, and says that he personally has not seen one.

McCrae and Caven (1926) reviewed 100 cases of tertiary syphilis of the liver, including five patients diagnosed as having congenital syphilis, aged 3,13 , 16,18 and 19 years respectively. In the latter the liver was diffusely enlarged but the exact histology was unrecorded. Hahn (1943) examined 66 tertiary syphilic livers at necropsy in adults, and pointed out that in only nine was the true diagnosis made in life. Shapiro and Weiner (1951) described a further 79 necropsies, all in adults, and made the observation that 'the visceral manifestations of late syphilis through their rarity have been neglected'. 
Flegel (1951) gave very detailed accounts of the livers in 22 children examined at necropsy at ages ranging from a stillborn infant to one aged $2 \frac{1}{2}$ years of age. All had syphilitic changes, but in very few had the liver architecture been replaced by granulation tissue, and in none was there a striking picture of naked-eye gummata, the liver being always enlarged but usually smooth. His account of the histology accords closely with that of Nabarro.

Jeans (1957) states that 'gummata may occur in almost any part of the body but they are rare in the liver, spleen and lungs'. He refers to one case he had seen which probably had gummata of the liver, but without any details.

Only one other reference to gumma of the liver, in an infant, was found in an article by Gerlóczy (1939), but this article could not be obtained. Isolated gummata of the pancreas (Raeburn, 1951), and the stomach (Willeford, Childers and Hepner, 1952) have also been recorded.

A recent report by Macfarlane, Johns and Schofield (1955) has emphasized these points. Their survey covered 200 patients with congenital syphilis of whom $172(86 \%)$ were found to have late syphilis. Of these, 105 had ocular lesions, including interstitial keratitis, optic atrophy choroiditis and iridocyclitis. Twentyfive had evidence of neurosyphilis, including juvenile and general paresis, tabes dorsalis, eighth nerve deafness, epilepsy and mental changes. Bone changes were found in 11 patients and joint changes in 16.

Only two patients had gummata, a girl of 9 years with a gumma of the larynx, and a man aged 28 years with a gumma of the testis, which had been removed as a malignant tumour.

These reports serve to emphasize the rarity of gumma in the viscera, and particularly in the liver, in childhood, and also the difficulty which may arise in diagnosis at any age. The striking features in this child are that such a condition can develop so early and with no other signs of the disease, presenting, as in many adults with tertiary syphilis, signs imitating malignant disease.

\section{Summary}

The case is reported of a child aged 6 years presenting with an isolated picture of gummata of the liver.

Allowing for the rarity of gummatous hepatitis in children, the remarkable ability of this disease to masquerade as other conditions serves as a reminder that a serological test for syphilis before operation in similar cases is worthy of consideration.

Carpenter, G. (1901). The Syphilis of Children in Every-day Flegel, H (1951)

Path. path. Anat., 87, 302.

Budapesti orvosi ujsâg., 37, 317

Hahn, R. D. (1943) Amer. J. Syph., 27, 529.

Hutinel, V. (1926). Bull. Soc. Pédiat. Paris, 24, 37.

Jeans, P. C. (1957). Brenneman's Practice of Paediatrics, Vol. 2, Ch. 26, pp. 9 and 33. Hagerstown, Maryland.

McCrae, T. and Caven, W. R. (1926). Amer. J. med. Sci., 172, 781.

Macfarlane, W. V., Johns, H. M. and Schofield, C. B. S. (1955). The Background of Congenital Syphilis. (Dept. of Venereology, Background of Congenital Syphilis. (De

Newcastle upon Tyne General Hospital.)
Nabarro, D. (1954). Congenital Syphilis. London.

Raeburn, C. (1951). J. Path. Bact., 63, 158.

Shapiro, E. and Weiner, H. (1951). Amer. J. med. Sci., 222, 494.

Willeford, G., Childers, J. H. and Hepner, W. R. (1952). Pediatrics, 10,162 . 